\title{
Corrigendum: Age-Related Vestibular Loss: Current Understanding and Future Research Directions
}

\section{Dominic Allen, Luis Ribeiro, Qadeer Arshad and Barry M. Seemungal*}

Division of Brain Sciences, Imperial College London, London, United Kingdom

\section{OPEN ACCESS}

Edited and Reviewed by: Yuri Agrawal,

Johns Hopkins University, United States

*Correspondence:

Barry M. Seemungal b.seemungal@imperial.ac.uk

Specialty section:

This article was submitted to Neuro-Otology, a section of the journal

Frontiers in Neurology

Received: 16 May 2017

Accepted: 21 July 2017

Published: 21 August 2017

Citation:

Allen D, Ribeiro L, Arshad $Q$ and Seemungal BM (2017) Corrigendum: Age-Related Vestibular Loss: Current Understanding and Future Research

Directions.

Front. Neurol. 8:391. doi: 10.3389/fneur.2017.00391
Keywords: vestibular system, aging, vestibular perception, vestibular apparatus, vestibular reflexes

\section{A corrigendum on}

Age-Related Vestibular Loss: Current Understanding and Future Research Directions by Allen D, Ribeiro L, Arshad Q, Seemungal BM. Front Neurol (2016) 7:231. doi: 10.3389/fneur. 2016.00231

Dominic Allen and Luis Ribeiro were not included as authors in the published article. The authors apologize for this error and state that this does not change the scientific conclusions of the article in any way.

The original article has been updated.

\section{AUTHOR CONTRIBUTIONS}

LR and DA: initial drafting of manuscript. QA: initial drafting and final revision of manuscript. BS: general organization of manuscript. Interim and final revision of manuscript.

Conflict of Interest Statement: The authors declare that the research was conducted in the absence of any commercial or financial relationships that could be construed as a potential conflict of interest.

Copyright (c) 2017 Allen, Ribeiro, Arshad and Seemungal. This is an open-access article distributed under the terms of the Creative Commons Attribution License (CC BY). The use, distribution or reproduction in other forums is permitted, provided the original author(s) or licensor are credited and that the original publication in this journal is cited, in accordance with accepted academic practice. No use, distribution or reproduction is permitted which does not comply with these terms. 